\title{
Universal Design and Study Abroad: (Re-)Designing Programs
}

\section{For Effectiveness and Access}

\author{
Heidi M. Soneson \\ University of Minnesota
}

Roberta J. Cordano

Allina Healthcare System

\section{Identifying the Need}

Study abroad in the United States is at a critical crossroads. University and college presidents are increasingly establishing internationalization as a central component of their institutional mission and publicly stipulating that a significantly higher percentage of students should have an international experience as part of their undergraduate program (Global Competence, 22). International experience is viewed as critical to preparing students to work in an increasingly interconnected and complex world. Academic departments on campus are responding by incorporating study abroad into their undergraduate graduation expectations and requirements and identifying opportunities for their students. Students are likewise responding to the heightened language on the value of international experiences and seeking information on viable opportunities. Over the last decade, the number of U.S. students studying abroad has more than doubled (IIE Open Doors 2006), resulting in an increased demand for study abroad options for students in a variety of majors, with differing backgrounds, and with a variety of health, physical and psychological needs.

Concurrent with this campus-based interest, the Lincoln Commission released its 2005 report with a clear national mandate: "the nation can and should establish a goal of one million students studying abroad by 201617." (Global Competence, viii) This represents a significant increase over the 223,234 U.S. students studying abroad (Open Doors 2007). If the U.S. Congress approves the Commission's additional recommendation to establish a fund of $\$ 50$ million in study abroad fellowships annually with an increase to $\$ 125$ million in year 2011-12, institutions can expect to see a rapid growth in the number and diversity of students seeking an international experience. 
As the number of students participating in study abroad programs grows, so will the range of students' functional abilities. In the case with students with disabilities alone, one part of the spectrum of functional abilities, Sally S. Scott, Joan M. McGuire, and Teresa E. Foley report that the number of students in post-secondary that self-reported a disability rose from $2.3 \%$ in 1978 to $9.8 \%$ in 1998.

In order to respond to this increased interest in international experiences, study abroad offices throughout the country are initiating expanded overseas opportunities for their students, and considering ways to include and serve new student constituencies. One critical population has been and continues to be underrepresented students. Underrepresented groups in study abroad include students of color, students with disabilities, and gay, lesbian, bisexual and transgender students, and over traditional age students.

As these programs expand, programmatic and institutional barriers will frustrate program administrators, both in the U.S. and abroad, and students. The threat of these issues interfering with the efficiency and effectiveness of programs is real. As institutions move toward requiring study abroad experiences as a degree requirement, they will need to identify and implement effective strategies for addressing the needs of a more diverse student population. This is not simply an issue of disability access, but one of program design.

Further, underrepresented students often face unique challenges in identifying programs where support systems and accommodations meet their particular needs. Students with disabilities, in particular, often require more detailed information on overseas sites in order to determine whether studying abroad on that program can be viable. While study abroad offices in the U.S. have increasingly gathered information to address the needs of these students, they tend to focus on the needs of a particular student applying for a particular study abroad site. This information is useful for an individual student, but it can often not be applied more generally or is not shared broadly.

Universal Design provides a framework to effectively increase the number of students studying abroad by creating and expanding supportive environments designed to meet a wide range of student needs. While the concept of Universal Design originated with the needs of students with disabilities, its value and application extend to a much wider student constituency. The concepts within Universal Design can be used to communicate information crucial for a wide range of students with specific needs who are considering study abroad programs, in order for them to assess access possibilities.

The importance of considering student needs as an important step in meeting the guidelines is underscored in education abroad professional publications. 
It is outlined in Responsible Study Abroad: Good Practices for Health E Safety, developed by The Interorganizational Task Force on Safety and Responsibility in Study Abroad. The Forum on Education Abroad's landmark publication, Standards of Good Practice for Education Abroad, specifically mentions disability access as an important consideration when establishing standards for organizational and program resources (Standards, 17). Both resources recommend that institutions conduct periodic assessments of health and safety conditions on their programs, provide health and safety information for prospective participants, and provide information concerning aspects of the home campus services and conditions that cannot be replicated at overseas locations. The concepts outlined in this article and the suggested assessment survey can assist institutions in considering the diversity of needs of students and, thereby, identifying in advance appropriate accommodations to help ensure the health and safety of program participants.

\section{Framing Access for students}

Recent legal cases have moved in the direction of relieving higher education institutions from a legal obligation of assuring equitable access for students with disabilities on study abroad programs. Questions have been raised about the applicability of U.S. disability rights laws to study abroad programs (See In re: Arizona State University, 2001; College of St. Scholastica (OCR 1992), and Bird v. Lewis and Clark College, 303 F3d 1015 (9th Cir. 2002). University policies requiring study abroad experiences will lead institutions requiring study abroad experiences to ask: (1) what are its obligations to assure that all students are provided with an opportunity to study abroad? (2) If it cannot assure that all students can study abroad, what other requirements or accommodations is it willing to consider as a substitute for the study abroad experience? (3) If it decides to substitute experiences, instead of providing reasonable accommodations abroad, is there an equivalent experience the student can have in the U.S. that will achieve the objectives sought by requiring study abroad experiences?

One way to enable greater access (both on U.S. campuses and in study abroad) is to view difference along a continuum of functional abilities. This means that the focus of analysis of program design is not on how to accommodate specific needs as defined by a label a person carries that may or may not be sanctioned by law. The focus of analysis is on the different types of functional capacities. By moving away from understanding the needs of participants from a legalistic perspective towards understanding the types of access each 
program offers, study abroad offices can make more effective programming decisions. By matching programs with the functional capacities of students, they can optimize opportunities in some locations that cannot be achieved in other locations. And, in some cases, this can allow students with certain functional limitations to experience a program, provided that all parties enter into the experience with an understanding of the challenges that may be experienced. After all, very few of us would deny that study abroad programs are often a test of resilience and ingenuity on the part of students when they experience new cultures and environments. An approach that allows programs, their staff and students to have a more comprehensive set of information to support decision-making will lead to more effective programming and greater access for all students.

We suggest four categories of functional differences: (1) Physical; (2) Sensory; (3) Cognitive: and (4) Emotional and Behavioral. Each of these is described below along with examples of how each functional ability may be manifested and typical modifications that may be made to meet the needs of individuals within each grouping.

\section{Physical Functional Differences}

Physical functional differences focuses on the ranges of abilities with two types of conditions: mobility conditions and systemic-related conditions. Mobility-related functional abilities focus on the different coordination abilities and/or abilities to move limbs or bodies. For example, some people will have complete or partial paralysis, leaving them with varying ranges of physical functional capacities. In other cases, people may suffer functional limitations as a result of muscle weakness, decreased flexibility, loss of balance, difficulty with dexterity and coordination, or limited ability to walk or climb stairs. Typical accommodations for those categorized as disabled include accessible transportation, adaptive technology, ramps, elevators, curb cuts, physical modifications and personal attendants.

Systemic-related functional abilities focus on conditions affecting one or more of the body's systems, including the respiratory, immunological, neurological, circulatory, or digestive systems. Systemic functional limitations can be created by conditions including diabetes, epilepsy, chronic fatigue syndrome, Lyme disease, lupus, multiple sclerosis, and multiple chemical sensitivity. Typical accommodations for those categorized as disabled include coursework accommodations (extra time on tests, obtaining a syllabus in advance), kitchen facilities and refrigeration, and access to medical facilities. 


\section{Sensory Functional Differences}

Sensory functional differences are related to the range of abilities with the body's senses, such as hearing, seeing, feeling, smell or taste. Hearing loss is the sensory functional difference that often presents the greatest challenge for higher educational institutions. A person who is deaf has a hearing loss of such severity that he or she depends primarily upon visual communication such as sign language, lip reading (also called speech-reading), writing or gestures. A person who is hard of hearing has a functional hearing loss, but may not depend primarily on visual communication. Typical accommodations for those categorized as disabled include sign language interpreters, note takers, real time transcription, TTDs (Telecommunication Device for the Deaf), TTYs (Teletext), closed captioning, and Audio Induction Loop, which transmit sounds to an amplifier device or hearing aid.

Vision loss is the other major type of functional difference. Individuals with vision impairments can have an eye condition that prevents them from reading text for extended periods of time, a significant loss in their field of vision, or total blindness. Typical accommodations for students with visual disabilities include early course preparation, mobility orientation to a particular classroom or location, tape recorders, alternate formats (such as Braille or large print), readers and scribes, assistants, and mobility guide dogs.

\section{Cognitive Functional Differences}

Cognitive functional differences are related to the range of neurological conditions that affect the ability to listen, speak, read, write, reason, or compute. These conditions can range from stuttering to a wide range in functional ability to read or write (e.g., learning disabilities) Typical accommodations for those categorized as disabled include testing accommodations/alternative assignments, note takers and tutors.

Other cognitive functional capacities that can be affected by various neurological conditions include balance, coordination, memory, and organizational and reasoning skills. These can be temporary or permanent conditions. Typical accommodations for those who are considered disabled include coursework accommodations, note takers, tutors, and counselors.

\section{Emotional and Behavioral Functional Differences}

Emotional and behavioral functional differences are the range of neurological conditions that manifest emotional or behavioral symptoms. Conditions include depression, bipolar disorder (manic depressive disorder), anxiety 
disorders, and schizophrenia. The functional capacities witnessed could include depressed moods, alternating periods of hyperactivity and depression, and the inability to concentrate. Though medication is frequently used to assist in regulating these behaviors, accommodations are often also provided. Typical accommodations for those whose conditions are considered disabling include extra time on tests, note takes, tutors, and counselors.

\section{The Value of Universal Design}

The five environments in the context of Universal Design, described below, can produce data and analysis that can meaningfully help study abroad offices assess and design, or in the case of many offices, redesign, their programs. The term Universal Design was coined by Ronald Mace in 1985, an architect who himself had a disability and who founded the Center for Universal Design at North Carolina State University (Saito 463). Mace argued that physical environments should be proactively designed to meet the need of a broadly diverse audience (McQuire 2006, 167). Since his initial insights, the principles of Universal Design have been implemented in architecture, engineering, product and landscape design, $\mathrm{K}-12$ education, higher education and in the workplace (Saito, 463).

Universal Design is defined as "the design of products and environments usable by all people to the greatest extent possible, without the need for adaptation or specialized design." (Center for Universal Design) The goal of Universal Design is to identify modifications that can serve the broadest audience possible and to have these structures and support systems in place proactively in order to avoid the need to adapt the environment specifically for each individual or create only a temporary adjustment based on a specific request. Creating structures that can appeal to a broad audience recognizes that a range of users might benefit from greater access and, thereby, fosters a welcoming environment. Having structures in place proactively increases efficiency by avoiding the need to retrofit an environment for each individual request (Scott, McGuire, Foley 2003, 41). Another important element of Universal Design focuses on creating environments in which accessibility is an integral part of the standard design and structure. Rather than creating modifications that require individuals to use a separate entrance or to request special assistance, Universal Design structures are planned as part of standard features in order to encourage integration and maximize the number of users who can easily access the accommodation (Scott, McGuire, Foley 2003, 41). 
This approach stands in dramatic contrast to the view that physical modifications, for example, are an anomaly to architectural design and that accommodations benefit only a specific audience, such as individuals with disabilities. The Association on Higher Education and Disability (AHEAD) clarifies the change in philosophy that Universal Design introduces:

- Environments designed universally serve all individuals simultaneously; the need for separate systems and multiple accommodations is minimized.

- Accessibility problems become the responsibility of the campus community ("the designers") to overcome; the environment is identified as the problem, not the individual.

- Accessibility standards are integrated during design rather than approached as an afterthought.

- The individual with a disability does not have to advocate continually for access; disability is viewed as a naturally occurring human difference and is addressed just as other individual variations are.

- Accessibility is built on and does not need to be re-addressed as each new individual encounters the environment and the curriculum. (AHEAD: "Universal Design in Higher Education")

The goal of Universal Design is to create a framework for identifying accommodations that can benefit multiple users. Examples of contemporary applications of Universal Design include close captioning on television, which benefits not only the hearing impaired but also individuals watching television in a noisy environment; curb cuts, which benefit wheelchair users and individuals pushing baby strollers; and universal signage, which is useful for those who have difficulty reading but also for individuals who may not know the language of the country (McGuire, Scott, Shaw 2003, 167). In these examples, a modification that may benefit one specific group of individuals has the advantage of broader applicability and thus makes the environment beneficial for a wider audience.

In 1998 Silver, Bourke and Strehorn explored the application of Universal Design to higher education as a means for making instruction more accessible. Silver and his colleagues studied the college environment in order to identify attitudes about effective teaching, instructional strategies that incorporated Universal Design, and barriers to implementing Universal Design. (Scott, McGuire, Foley, 2003, 40). Silver, Bourke and Strehorn determined that some faculty already utilized instructional practices that were inclusive and that applying Universal Design to the classroom would not necessarily require the implementation of a 
new teaching approach. Instead Universal Design could assist in identifying additional ways to incorporate the needs of a diverse student body in instructional planning (Scott, McGuire and Foley 2003, 41). Scott, McGuire and Foley build on this idea in their research and argue that Universal Design can "provide tools for addressing disability access and other legitimate students needs in a proactive way that preserves the integrity of the course while promoting learning for a broader range of students." (Scott, McGuire, and Foley 2003, 41)

Seven guiding principles facilitate the implementation of Universal Design in a variety of settings. In order to understand the value of Universal Design and its applicability, it is important to consider these seven principles and the approach they foster. These principles are designed to foster creative exploration of ways to apply Universal Design rather than identify prescriptive measures of implementation (Saito, 464). In the area of classroom learning, they provide " a framework for faculty planning and practice rather than a rigid procedure or prescription for instruction" (Scott, McGuire and Foley 2003, 43). The examples that follow illustrate ways in which each principle is applied to a Universal Design modification.

\section{Principle 1: Equitable Use}

The design is useful and accessible to students with a diverse range of abilities. An example of a Universal Design adaptation in the classroom is to provide class notes on-line so that they can be accessed by all students regardless of their hearing ability, English proficiency, learning or attention disorders, or note taking skills. Since the same means is provided to all students, "differential treatment or stigmatizing of students" is avoided. (Scott, McGuire and Foley, 43)

\section{Principle 2: Flexibility.}

The design accommodates a wide range of individual abilities. An example in the classroom is to provide students with a choice in the assessment methods (exam, paper, or on-line project). This allows students with differing abilities or experiences to select the medium that best demonstrates their skills.

\section{Principle 3: Simple and Intuitive.}

The design is in a straightforward and predictable manner "regardless of a student's experience, knowledge, language skills, or current concentration level" (Scott, McGuire and Foley, 44). A classroom example is a textbook that includes study questions, chapter outlines and key vocabulary to provide students with multiple formats for learning the required information. 


\section{Principle 4: Perceptible Information}

Information is communicated effectively regardless of a student's sensory abilities. A classroom example is to utilize PowerPoint in the classroom presentation as a supplemental mode of communication.

\section{Principle 5: Tolerance for Error}

The design anticipates variation in student learning rates. A classroom example is to allow students to submit a draft version of an assignment to enable additional skill building.

\section{Principle 6: Low Physical Effort}

The design allows maximum attention to learning. A classroom example is to provide reading materials in binders that can be separated to reduce the amount of material that must be brought to class.

\section{Principle 7: Size and Space for Approach and Use}

The design considers appropriate size and space for approach, reach, manipulation, and use regardless of a user's body size, posture, or mobility. A classroom example is height adjustable desks and computer stations to address the needs of students in wheelchairs or students who are unable to sit for extended periods of time due to chronic back pain.

The value of a Universal Design approach for study abroad is multifold. First, programs can prepare a context that attracts and is accessible to a wide variety of applicants rather than address each individual request as it arises. By making a variety of accommodations standard program features, these features are in place and accessible for any arriving student. This is more efficient for U.S. advisors and on-site staff, because new structures and adaptations do not need to be created on short notice. Second, information on these structures and accommodations can be stated clearly in program materials as standard program features. This enables students to be better informed and to make a more accurate assessment of the program's environment. Third, a Universal Design approach can reduce the amount of effort that is currently dedicated to fostering disclosure or addressing needs that are identified only once the student arrives at the study abroad program. By having a variety of accommodations in place as a permanent feature of the program, the program is better able to adapt to a variety of student needs. Finally, the Universal Design approach can help create a more flexible on-site environment. By systematically considering 
the variety of accommodations that can be implemented on a particular study abroad program, the program staff is in a better position to respond to requests and accommodations needs as they arise.

At the same time, study abroad offers a unique challenge in applying Universal Design as any modification must be feasible within the cultural, institutional, and physical realities of the overseas context. Consideration of what is possible is the first step in identifying modifications that help create greater access to study abroad programs.

\section{The Five Environments in the Study Abroad Context}

Five essential environments shape the student experience and form critical components of the study abroad context. The flexibility each program will have to modify these environments depends on the nature of the program and the level of control it has over its setting. In the following sections, each environment is described, along with key subcategories that fill out the detail. Examples of how a study abroad program can incorporate concepts of Universal Design in each environment are provided.

\section{Physical Environment}

This includes access in buildings, housing arrangements, transportation and public spaces. Information would include whether a classroom or a dormitory is located on the ground floor, if necessary, whether visual alert systems be placed in the dormitory to assist someone who is hard of hearing in case of an emergency, and how far the housing is from the classroom for a student with a mobility disability. This environment would also include program-sponsored excursions and the extent to which programs can arrange alternative modes of transportation to meet student access needs. Key subcategories in this environment include:

Residential facility: location (distance to classes, daily needs, transportation), access (level, entrance size/type, door knobs), occupancy (access to privacy, guest options), amenities (bathroom design, lighting, lighting, type of bed), notification systems (emergency alert systems),

Classroom: location (distance to housing, transportation,) access (level, entrance size/type, door knobs), physical layout (seating arrangements, flooring, distance to instructor,) amenities (lighting, technical equipment, window dressings) Program Office: location (distance to housing, transportation), access (level, entrance size/type, door knobs), student work space (movable desks, computer equipment, privacy), consultation (location, access, mobility) 
Public space/Excursions: daily travel (commuting options, street accessibility, signage), transportation (type of transportation, alternate options, accessibility), daily living (shopping access)

Physical Environment Example 1: A study abroad program that offers multiple housing options includes additional information in its program materials on the availability of accessible housing, including wheelchair accessible housing, the possibility of having a dedicated companion share a room with a student who needs this level of support, and whether public transportation is accessible for someone with a mobility disability. Photos of or web links to the program housing can provide inquiring students with helpful information early in the application process.

Physical Environment Example 2: An overseas study abroad center offers courses in a building that has classrooms on several floors. There is no elevator, and one cannot be installed. Nonetheless, the center is able to purchase some desks with adjustable heights to allow for some accommodation needs, and the desks and chairs can be moved to different locations in the classroom for students who may need to sit close to the speaker for hearing or visual purposes. In addition, the center determines that it can locate a classroom on the ground level for its short-term, faculty-led program that will allow students with significant mobility disabilities to participate.

\section{Academic Environment}

This includes the classroom setting and instructional methods. Adaptations focus on the ability to change the classroom layout, offer instructional materials in different formats, provide syllabi in advance, and modify testing arrangements. Key subcategories in this environment include:

Teaching Materials : syllabus availability in advance

Teaching styles/Dominant learning mode : lecture, discussion, on-line

Discussion format: round-robin, facilitator, electronic communication via laptops, sound systems

Information Dissemination: physical equipment (blackboard, PowerPoint, overheads, handouts)

Academic Environment Example: A study abroad program that organizes its own courses posts syllabi to its web site for students to access in advance. This not only assists students who may need syllabi translated in advance into 
alternate formats such as Braille or large print, it allows any student access for academic credit purposes. For programs that rely primarily on courses offered by an international university, course descriptions for the most popular courses are posted. Information is also made available on program web sites and in program materials on how course materials are presented in the classroom.

\section{Cultural Environment}

This environment addresses attitudinal assumptions regarding disabilities and the extent to which the range of disabilities commonly identified in the U.S. are recognized overseas. This environment also includes social interactions in a non-academic context, specifically to what extent students with differing conditions are able to integrate into the social fabric of the overseas culture and find social venues in which they will be accepted. Key subcategories in this environment include:

Excursions: accessibility, access options, presentation of information

Physical space: size of facility, number of attendees, seating options

Interaction: individual, small group, large mingling

Organization/Notification: planned or spontaneous, access to schedule, information available in advance of required action, frequency

Cultural Environment Example: A U.S. study abroad program references the general level of accessibility on its program web site as part of its initial promotional information, the structure and number of excursions and social activities offered. It also provides helpful links and more detailed information in its various program materials for these sites so that students can inform themselves about accessibility at these various venues.

\section{Informational Environment}

The informational environment focuses on the ways in which students access information about the overseas program and possible accommodations. Vehicles for information distribution include program or institutional web sites, printed promotional materials, orientation handbooks, and on-site newsletters. The ability to modify the way in which information is provided during city tours or program excursions would also apply to this environment. Key subcategories in this environment include:

Program Materials: format (verbal, written, electronic, signage), notification (available in advance of required action, frequency), resources (local support services, local student groups/welcoming environments) 
Informational Environment Example: Information on support services available in the overseas local community is included in program materials that are easily available to students considering study abroad. This information could include university-based support offices, student groups, and learning resource centers.

\section{Policy/Programmatic Environment}

This environment is reflected in the guidelines around student participation and the level of openness reflected in program materials and staffing. This includes how many courses a student needs to take on the program, how many hours per week and per day is the student typically in the classroom, and any flexibility that may exist regarding these requirements. It also clarifies what support offices on campus can help students with the application process and possible accommodation needs, how to ensure that promotional materials reflect the diversity of participants, and what training can be provided to office staff to increase awareness of diverse needs. Key subcategories in this environment include:

Statements: inclusive statements in program materials, web site, promotional materials

Visual Statements: expressing openness (messages conveyed through art, decorations)

Staffing: level of sensitivity (staff/faculty training, body language, life experiences)

Inclusivity: staffing representative of differences

Support Services

Student Contacts: access to local students with differences

Contacts: coordinating offices

Program Materials: inclusive statements, formats available

Promotional Materials: inclusive photos, inclusive statements

Forms: multiple access points, disclosure opportunities

Evaluation \& Feedback: questions related to disclosure \& services

Policy/Programmatic Environment Example: A study abroad program includes with its general information on courses more detailed information on a student's typical weekly schedule and how many hours per day and per week a student spends in the classroom. It provides links on its web site to the support office on campus that can facilitate any accommodations that might be needed for alternative application formats, or provide additional advising 
assistance. The study abroad program web site also includes short interviews with students who have functional differences and what accommodations were provided on their study abroad program.

Providing information in each of these environments and subcategories will help a student anticipate the overseas situation and be able to seek clarification on any possible specific accommodations that s/he might need. This not only helps the student make an informed decision about which program is most suitable, it also allows study abroad offices to create a more welcoming environment for student disclosure.

\section{The Access Assessment Survey}

The ability of study abroad programs to identify ways to offer flexibility in one or more of these categories will help define its ability to reach out to a variety of student needs. To assist programs in identifying potential modifications for each environment, an Access Assessment Survey is provided. This survey allows programs to assess their current situation and think creatively about future options. Once a program has identified program design possibilities, the information should be included in program and promotional materials to help inform inquiring students. This enables students to learn about the realities of a particular location and thus minimize the assumptions about access that are frequently made due to lack of knowledge about the overseas context. It reduces the need for pre-program disclosure as the primary means of conveying access information to students, because the program materials already provide much of the needed information. Providing this additional information can also foster disclosure, because students will see that thought and attention has been given to the realities of a diverse audience. This ultimately helps to foster an open welcoming environment.

There are three key questions to consider when assessing ways to expand accessibility:

1. What modifications can be made to provide similar access for each functional difference (physical, sensory, cognitive, emotional and behavioral)?

2. If a modification cannot be made, are there alternatives or other resources?

3. How will the modification benefit other participants?

These questions will help elicit access possibilities both for students with disabilities and ways in which these modifications can appeal to a broader audience. 
The Access Assessment Survey asks U.S. and overseas program staff to provide details by filling in a table about the current situation in each environment, and then consider the ways in which each environment could be modified, either temporarily or permanently.

The first two columns of the table ask for the current status of each environment. The next columns identify the major functional categories. The final two columns ask for identification of alternative resources, and of the benefits of the options for all program participants. The rows on the Access Assessment Survey go through each of the five environments and key subcategories within each environment.

A representative sample of the Access Assessment Survey, completed for one environment, Physical, Residential subcategory, is shown in Figure 1. A fully completed Access Assessment Survey for a program or site would consider each of the five environments and provide details for each of the subcategories listed earlier in this article.

In order to use the Access Assessment Survey effectively, communication among the U.S. study abroad office and advisor, overseas staff, and, as necessary, the U.S. campus disability services office is essential. The Access Assessment Survey is designed to be flexible in order to accommodate the range of physical, social, and cultural contexts that exist overseas. Study abroad programs may discover that some categories contain areas that are more easily adaptable than others. Overseas sites should provide information that fully addresses on-site realities under each environment.

The survey focuses primarily on the academic classroom environment. Sites that offer internships or volunteer opportunities can utilize the survey to consider what kind of accommodations might be possible at specific internship or volunteer locations. The Access Assessment Survey is also designed to encourage programs to revisit their accessibility over time in order to identify new accommodation possibilities as programs implement technological changes, expand office and classroom space, and receive students with newly identified accommodation needs. Again, the goal of this Access Assessment Survey is to encourage study abroad programs to reflect on their particular environment and engage in creative exploration of ways to expand accessibility at their site. 


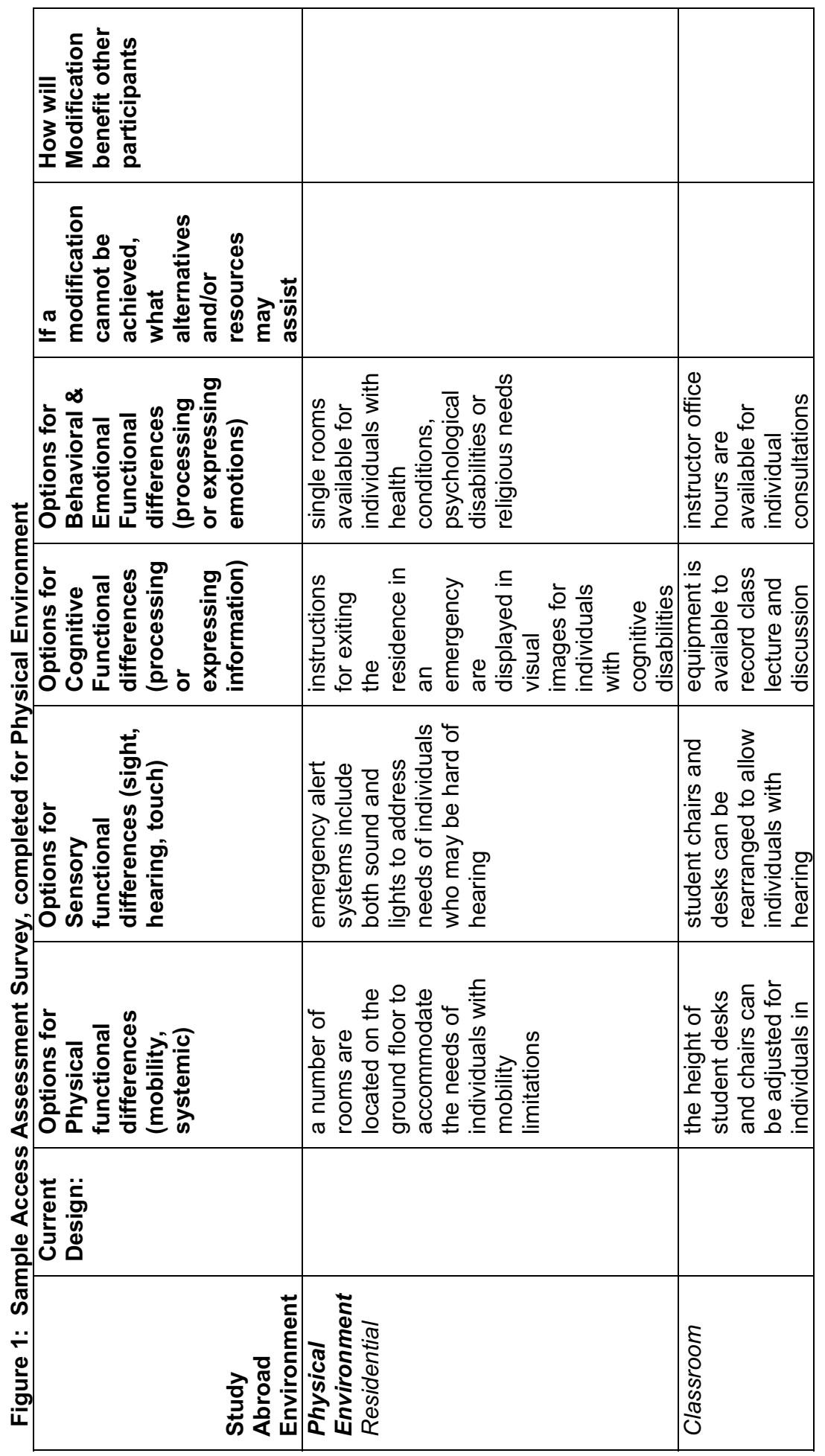




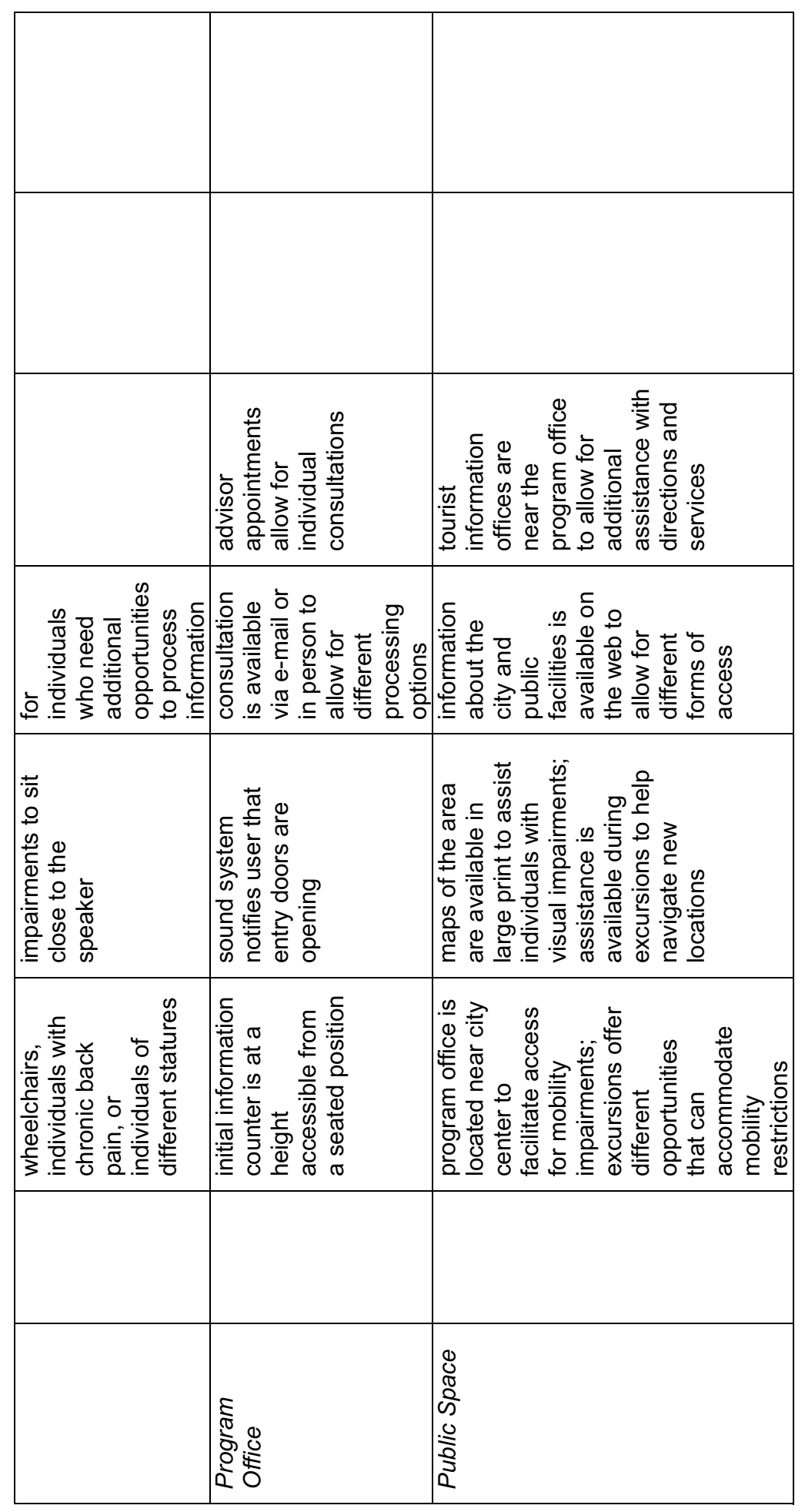




\section{Conclusion}

This article provides study abroad programs with a new and innovative way to create a more responsive overseas context for the growing range of students studying abroad. By utilizing the Access Assessment Survey to consider ways to meet the needs of students with various functional differences, U.S. institutions and overseas providers can identify the program modifications and design changes required to benefit a variety of student learning and living needs. In order for study abroad to be an integral part of the U.S. student's academic experience and, in this process, help to create informed citizens, it must be accessible to many different learners. Identifying and addressing the needs of students with functional differences is an important step in this direction.

\section{Works Cited}

Association on Higher Education and Disability. (n.d.) Universal design in higher education [Brochure]. Waltham, MA: Association on Higher Education and Disability

Breslin, M. \& Yee, S. (2005). International law and policy. In S. S. Sygall \& M. Scheib (Eds.), Rights and Responsibilities: A guide to national and international disability-related laws for international exchange organizations and participants. (pp. 29-38). Eugene, OR: Mobility International USA.

Brown University. (n.d.) www.brown.edu/Administration/Dean_of_the_College/uid/html/foreign.shtml

Canadian Human Rights Commission. (2006). International best practices in universal design: A global review. Ottawa, Canada:Betty Dion Enterprises Ltd.

Center for Applied Special Technology. (n.d.). www.cast.org

Center on Postsecondary Education and Disability. (n.d.). www.cped.uonn.edu.

Embry, P., Scott, S., \& McGuire, J. (2004). The legal context for postsecondary students with disabilities, institutions of higher education, and faculty members.

Storrs: University of Connecticut, Center on Postsecondary Education and Disability.

European Agency for Development in Special Needs Education. (2006). Special needs education in Europe: thematic publication: provision in post-primary education/ European Agency for Development in Special Needs Education. Odense: European Agency for Development in Special Needs Education.

Global Competence and National Needs: One Million Students Studying Abroad. Commission on the Abraham Lincoln Study Abroad Fellowship Program. November 2005. http://www.aplu.org/NetCommunity Page. aspx? pid $=731$ 
Golden, M. (2005). The civil rights of travelers with disabilities: The impact of the Americans with disabilities act and other disability civil rights laws. In S. S. Sygall \& M. Scheib (Eds.), Rights and Responsibilities: A guide to national and international disability-related laws for international exchange organizations and participants. (pp. 15-26). Eugene, OR: Mobility International USA.

Gore, J. E. (2005). Policy implications. In Dominate beliefs and alternative voices: Discourse, belief, and gender in American study abroad. New York: Routledge.

Hebel, S. (2002). Advocates for students with disabilities criticize education dept. ruling on study-abroad program. Chronicle of Higher Education, 48(18), A31.

Johnson, D. (2000). Enhancing out-of-class opportunities for students with disabilities. New Directions for Student Services, 91, 41-53.

Kanter, A. S. (2005). The right of students with disabilities to equal participation in study abroad programs. In S. S. Sygall \& M. Scheib (Eds.), Rights and Responsibilities: A guide to national and international disability-related laws for international exchange organizations and participants. (pp. 41-45). Eugene, OR: Mobility International USA.

Keen, K. (2005). Arranging for sign language interpretation abroad: A disability service provider perspective. In S. S. Sygall \& M. Scheib (Eds.), Rights and Responsibilities: A guide to national and international disability-related laws for international exchange organizations and participants. (pp. 89-91). Eugene, OR: Mobility International USA.

Lebold, C. J., Henry, A., Houston, P., Jackson, M., Scheib, M., \& Van Der Meid, S. (2007). Reaching underrepresented constituencies. In J. L. Brockington, W. W. Hoffa, and P. C. Martin (Eds.), NAFSA's guide to Education abroad for advisers and administrators (207-238). Washington D. C.: NAFSA: Association of International Educators.

Madaus, J. W., Scott, S. S., and McGuire J. M. (2003). Barriers and bridges to learning as perceived by postsecondary students with learning disabilities (Tech. Rep. No. 01). Center on Postsecondary Education and Disability, University of Connecticut.

McGuire, J. M., Scott, S. S., and Shaw, S. F. (2006). Universal design and its applications in educational environments. Remedial and special education 27(3), 166-175.

McLeod, L. \& Scheib, M. (2005). A practice of yes! Eugene, OR: Mobility International USA.

Mobility International USA. (2004). Checklist for inclusion. Excerpt from building an inclusive development community: A manual on including people with disabilities in international development programs. 
NAFSA: Responsible Study Abroad: Good Practices for Health E Safety. (2002). Washington D. C.: The Interorganizational Task Force on Safety and Responsibility in Study Abroad.

National Bureau for Students with Disabilities. (2007). The Skill Journal. June(88).

North Carolina State University. (n.d.). http://www.design.ncsu.edu/cud/

Parker, D. R., Embry, P. B., Scott, S. S., and McGuire J. M. (2003). Disability service providers' perceptions about implementing Universal Design for Instruction (UDI) on college campuses (Tech. Rep. No. 3). Center on Postsecondary Education and Disability, University of Connecticut.

Saito, Y. (2006). Awareness of Universal Design among facility managers in Japan and the United States. Automation in Construction 15(4), 462-478.

Scheib, M. (1999). Intercultural negotiation in Spanish-speaking countries: Perceptions of U.S. students with disabilities in study abroad. Unpublished doctoral dissertation, University of Minnesota, Minneapolis.

Scott, S. S., McGuire, J. M. and Foley, T. F. (2003). Universal Design for Instruction: A framework for anticipating and responding to disability and other diverse learning needs in the college classroom. Equity E Excellence in Education 36(1) 40-49.

Sygall, S. S \& Scheib, M (Eds.), Rights and Responsibilities: A guide to national and international disability-related laws for international exchange organizations and participants. (pp. 89-91). Eugene, OR: Mobility International USA. University of Washington. (n.d.). www.washington.edu/doit/

Wehmeyer, Michael L. (2006). "Universal Design for learning, access to general education curriculum and students with mild mental retardation". Exceptionality 14(4), 225-235.

Zola, I. K. (1989). Toward the necessary universalizing of a disability policy. The Milbank Quarterly, 67(2), 401-428.

Zola, I. K. (1993). Disability statistics, what we count and what it tells us: A personal and political analysis. Journal of Disability Policy Studies, 4(2), 9-39. 